\title{
"Ejemplos" indígenas, el Covi-cho y algunos tips anti fines de mundo
}

\author{
CELESTE MEDRANO \\ Universidad de Buenos Aires, Buenos Aires, Argentina \\ celestazo@hotmail.com
}

DOI 10.11606/issn.2316-9133.v29isuplp173-181

\begin{abstract}
resumen El objetivo del presente ensayo es poner en diálogo ciertas perspectivas de fines de mundo narradas por los indígenas qom del Gran Chaco Argentino y los sucesos desplegados por la actual pandemia de COVID-19. Con el fin de 'amansar' al virus, lo llamaremos Covi-cho y lo situaremos en tensión con los 'modelos' y 'ejemplos' que el antropólogo Viveiros de Castro propuso en un manuscrito del 2019. Como mostraremos, los fines del mundo para los colectivos indígenas de Argentina se han presentado una y varias veces, al ritmo de la creación de la nación moderna. No obstante esto, ellos siguen ahí, resistiendo en sus devenires. En un contexto como el contemporáneo, donde los Estados ensayan 'modelos' para proteger la salud de los ciudadanos, nos preguntaremos: ¿pueden estos 'ejemplos' indígenas enseñarnos algo sobre la actual crisis sanitaria global?

palabras claves Pensamiento indígena. COVID-19. Qom (Tobas). Gran Chaco.

\section{Exemplos indígenas, o Covi-cho e alguns tips contra o fim do mundo}

resumo $\mathrm{O}$ objetivo do presente ensaio é pôr em diálogo certas perspectivas de fim de mundo narradas pelos indígenas Qom do Gran Chago argentino e os eventos decorridos da atual pandemia de COVID-19. Com o propósito de "amansar" o vírus, iremos nomeá-lo Covi-Cho e o situaremos na tensão entre "modelos" e "exemplos" que o antropólogo Eduardo Viveiros de Castro propôs em texto de 2019. Como mostraremos, os fins de mundo para os coletivos indígenas na Argentina têm se apresentado vez e outra ao ritmo da criação da nação moderna. Contudo, eles permanecem lá, resistindo em seus devires. Em um contexto como o contemporâneo, onde os Estados ensaiam "modelos" para proteger a saúde dos cidadãos, nos perguntamos: podem estes "exemplos" indígenas nos ensinar algo sobre a presente crise sanitária global?
\end{abstract}

palavras-chave Pensamento indígena. COVID-19. Qom (Tobas). Gran Chaco. 


\section{world \\ Indigenous's 'examples', the Covi-cho and some tips against the ends of the}

abstract The objective of this essay is to put into dialogue certain perspectives of the ends of the world narrated by the Qom indigenous people of the Argentinean Gran Chaco and the events unfolding by the current COVID-19 pandemic. In order to 'familiarize' the virus, we will call it Covi-cho and place it in tension with the 'models' and the 'examples' that the anthropologist Viveiros de Castro proposed in a 2019 manuscript. As we will show, the ends of the world to the indigenous groups of Argentina have performed once and several times, at the rhythm of the creation of the modern nation. Despite this, they are still there, resisting in their accretions. In a context like the contemporary one, where the States are testing 'models' to protect the health of citizens, we will ask ourselves: can these indigenous 'examples' teach us something about the current global health crisis?

keywords Indigenous thinking. COVID-19. Qom (Tobas). Gran Chaco.

\section{Presentación}

Tripulante del día 70 de la cuarentena argentina, enumerando así las jornadas, sin saber bien en qué semana o mes estamos, y en grave estado mental bricoleur, empiezo este ensayo. El bricoleur, tal como lo definió el célebre Claude Lévi-Strauss para describir al pensamiento mítico indígena, utiliza medios desviados, rebota, divaga, se aparta de la línea recta para evitar un obstáculo. El antropólogo francés profundiza: las reglas del juego de un bricoleur son "arreglárselas con 'lo que uno tenga', es decir un conjunto, a cada instante finito, de instrumentos y de materiales, heteróclitos, además, porque la composición del conjunto no está en relación con el proyecto del momento, ni, por lo demás, con ningún proyecto particular" (1964, p. 36). Así, henchida de recuerdos personales, trozos bibliográficos, imágenes de películas cataclísmicas, mitología indígena, alcohol al 70\%, en aislamiento, tras la trinchera de la puerta de mi casa, comienzo este texto consumadamente ecléctico con el fin de amalgamar materias que parecen invocar a dos mundos inconmensurables: el del Covi-cho -sabrán más adelante el porqué de esta invención- y lo que aprendí junto a los $q o m^{1}$. Pero una no empieza un experimento completamente a ciegas. Lévi-Strauss decía que el pensamiento bricoleur nos permite develar relaciones que, vistas con otro tipo de anteojos, tienen la impronta de lo intolerable. Avanzo entonces, con esperanzas manufactureras, con

\footnotetext{
${ }^{1}$ Los qom (o tobas) conforman un colectivo indígena de grupos familiares que antiguamente se dedicaba a la caza, la pesca y la recolección como modo de subsistencia. En la actualidad residen en comunidades rurales en el noreste de Argentina o en barrios ubicados en los márgenes de grandes urbes (Buenos Aires, Santa Fe, Rosario, Resistencia, Formosa, entre otras). Los que aún moran en regiones de su antiguo territorio no viven exclusivamente del monte y sus recursos ya que la expoliación territorial, la sedentarización y la colonización condicionaron el acceso a los antiguos lugares de aprovisionamiento. Actualmente los qom constituyen la sociedad indígena más populosa del Gran Chaco: una vasta llanura semi-árida que se extiende sobre parte del norte de Argentina, del este de Bolivia, del oeste de Paraguay y del centro-oeste de Brasil, a lo largo de un millón de kilómetros cuadrados.
} 
los trozos de lo que tengo y de lo que soy, de lo que leí y vi hacia un horizonte de vínculos que nos puedan emancipar de tanto cautiverio.

\section{Advertencias y lecturas iniciáticas}

Advierto que decidí no escribir la palabra Coronavirus (salvo esta vez, claro) pues entre otras razones ${ }^{2}$-, rebautizarlo fué 'familiarizarlo' (FAUSTO, 1999). La invención Covicho, mezcla la palabra bicho (bi-cho), que remite a un conjunto multiforme de animales pequeños y a veces intratables, y la palabra virus (vi-rus) posibilitándome ponerlo bajo mi propia lupa, esa que viene mirando no-humanos hace años, y dotarlo de un carácter de sujeto que me permita reflexionar 'sobre' pero también 'con' este vi-cho/virus que -infectándonos o no- parece estar cómodamente instalado en nuestros hogares marcando el ritmo de una atípica vida ya en setentena. También confieso que voy a mezclar al Covi-cho y al pensamiento indígena porque, simplemente, no sé hacer otra cosa; estoy des-formada para eso. Desde el 2008, comencé a aprender zoologías indígenas. Más precisamente, me fui a vivir a El Desaguadero, una comunidad al noreste del Gran Chaco (en Formosa, Argentina), y empecé de a poco a formarme en la zoología qom. Me enseñaron cómo se cazan y utilizan los animales, pero también cómo se clasifican, cuáles son sus fisiologías, sus anatomías, sus personalidades. Todo esto en un contexto donde el límite entre la humanidad y la animalidad se tornaba, con cada paso del aprendizaje, más difuso y tanto los hombres y las mujeres como la fauna no-humana trazaban el pulso de la socialidad (MEDRANO, 2013; 2014; 2016 a y b; 2019).

Así, me vi durante una de estas tardes de aislamiento intentando dialogar con el Covi-cho desde esta perspectiva que aprendí junto a los qom. Preguntándome que dirían o me enseñarían ellos en este momento tan dramático e indagando sobre la incidencia de un pensamiento indígena frente a tanta pandemia de información desesperante. Dicha empresa me remitió a un texto que otro antropólogo, Eduardo Viveiros de Castro, escribió en 2019. El autor reflexiona situado en el Antropoceno -esta nueva época geológica donde la actividad humana representa la fuerza principal que altera radical e irrevocablemente a la tierra que habitamos- y concluye que nos urge practicar una "forma radical de pluralismo ontológico" si queremos seguir figurando sobre la faz del planeta. Pero: ¿qué significa esto? Para simplificar, comenzamos mencionando que una ontología es una forma de entender y percibir las continuidades y discontinuidades existentes entre humanos y no-humanos. Explicado de manera bien rápida podríamos decir que, por ejemplo, en el seno de un grupo moderno como el que se despliega en una urbe metropolitana, la sociedad sólo se concibe organizada por humanos y por sus humanos principios, reglas y aspiraciones. En cambio, en ciertos colectivos indígenas -por ejemplo, entre los shuar de la Amazonía ecuatoriana, o entre los mismos qom del Gran Chaco argentino-, las reglas sociales son dirimidas entre

\footnotetext{
${ }^{2}$ Pueden leer esas otras razones en un ensayo de divulgación que escribí al inicio de la cuarentena en argentina y está disponible en el siguiente link: https://lavoragine.net/covicho-ejemplos-indigenas-tips-antiantropoceno/
} 
humanos y no-humanos; aquí las 'madres' y los 'padres' de las especies animales y vegetales tienen tanta voz y voto como el cacique o el chamán. "En el Antropoceno ningún modo de existencia puede ser descartado como ilegítimo”, pregona Viveiros de Castro, pero ¿Cómo hacerle espacio a los modos y formas de los demás? Este antropólogo brasileño llama a abandonar parcialmente los 'modelos' -estos instrumentos políticos que siempre implican relaciones de poder asimétricas- que tienden a enderezar las destrucciones antropocénicas o a, volviendo al tema del ensayo, dirigir el curso de la pandemia de Covi-cho. Llama entonces a volvernos hacia lo que él llama los 'ejemplos', estas formas de acción y pensamiento que, desplegadas por muchos pueblos indígenas -si logran sobrevivir a los 'modelos'-, funcionan como incentivo para hacer una versión diferente, para operar en transformación. Los 'modelos' "dan órdenes y hacen cumplir la orden; los ejemplos, en cambio, dan pistas, inventos inspiradores y subversiones" (VIVEIROS DE CASTRO, 2019, p.301).

\section{Traducciones domésticas y fines de mundo}

¿Cómo traducir todo esto en un ejemplo doméstico que nos permita repensarnos? Y aquí, permítanme un eurekismo autorreferencial, una manzana (la idea) que no hace más que caer en el centro de mi propia biografía. Cuando tuve a mi primer y único hijo decidimos ponerle Lalac (son seudónimos, claro), un nombre que yo había aprendido durante mi trabajo con los qom, en definitiva, un nombre indígena. No obstante, durante las largas mañanas que se sucedieron al nacimiento y nos hallábamos el bebé y yo solos, pues el padre salía a trabajar, me encontré dos veces en una escena de completa intimidad -luz tenue, la teta, la tibieza de Mayo-, llamando a mi hijo Teseo. Un mediodía, cuando el padre regresó al nicho de amamantamiento, yo deslicé que le podríamos cambiar al niño el nombre original de Lalac por el de Teseo, pues el segundo 'me había bajado', o ‘había bajado al bebé -era el nombre que lo 'estaba haciendo'. Conclusión, cada vez que yo cuento esta anécdota remato afirmando: mi hijo tiene un nombre indígena que le fue puesto de forma occidental y tiene un nombre occidental que le fue otorgado siguiendo la manera indígena.

Volviendo a los 'modelos y ejemplos' de Viveiros de Castro, cuando el antropólogo llama a seguir ejemplos indígenas, no nos demanda la 'forma' sino la 'manera', no nos pide que embanderemos los patios de la Wipala -en definitiva que le pongamos nombres indígenas a lo que decimos y hacemos- y les organicemos altares a dioses de desconocido temperamento; reclama que observemos el contenido de los devenires de colectivos que organizan sociedades co-protagonizadas por humanos, no-humanos, fenómenos meteorológicos, ríos, piedras, montañas -y por qué no virus y bacterias. Que miremos las maneras en las cuales dichos colectivos devienen en multiplicidad y, sobre todo, que observemos su ejemplo: ellos han sobrevivido a diversos Antropocenos, para ellos el fin del mundo llegó una y varias veces. Para los qom, por ejemplo, primero desembarcaron los ejércitos que los asesinaron sin piedad, luego el evangelio y las epidemias de viruela que diezmaron sus cuerpos y mutilaron sus almas. Valentín Suarez, líder indígena de la comunidad Riacho de Oro de Formosa me narra a través de un mensaje de Whatsapp: "la 
verdad que la magnitud [de la pandemia de Covi-cho] es como ra'loxo [la viruela] el contagio fue en el ingenio Ledesma y huyeron varios para Chaco y Formosa ${ }^{3}$. Para no ser contagiados, porque a los 2 o 3 días ya muere la persona infectada, pero dicen que había vacuna de ese virus. Viruela. Algunos [se vacunaban] cuando ya volvían en el tren carguero. Pero murieron muchísimos". También fueron expulsados de sus territorios, vieron sus casas arder, fueron objeto de tortura y aún lo son, pues no hemos podido construir un Estado que respete sus formas de educar, curar, rogar, festejar, conseguir alimentos, etc. Incluso, los fines del mundo para los colectivos indígenas de toda Argentina se han presentado una y varias veces, al ritmo de los devenires de la creación de la nación moderna. No obstante, esto, ellos siguen ahí, resistiendo en sus haceres y decires.

Pero: ¿cómo seguir la 'manera' indígena sin ningún tipo de información al respecto? No cuento con recetas magistrales y sospecho que hay que poner cuerpo y mente a remojar en miles de textos y sobre todo en el devenir otro. No obstante, me voy a animar a resumir ahora uno de los fines de mundo de los qom -tan sólo uno, si quieren leer sobre los otros pueden consultar el libro de Florencia Tola y Valentín Suárez (2016)- con ánimos de formular algún tipo de reflexión sobre el exterminio total con el que nos amenaza el Covicho, el aislamiento social preventivo y obligatorio al que nos somete el Estado y las 'maneras' indígenas de salir de una desaparición mundial generalizada. Este fin de mundo qom llamado 'El diluvio de fuego' fue narrado por Mariano Noel, un indígena, y transcripto por Buenaventura Terán (2005), un antropólogo rosarino:

La tierra se quemaba. Y parecía el fin del mundo. Se quemó entera la tierra. Los animales murieron; también, los hombres. Pero a una gente le avisaron que cavaran un hueco. Hicieron una excavación grande. Porque había un aviso que decía: "Hagan un hueco porque viene el fuego". Se quemaba arriba de la tierra. Abajo se guardaban. Era un pájaro el que avisó. Con la fruta de algarrobo, prepararon comida para cuando entraran al hueco. Entraron. Muchos entraron. Se quemó la tierra. Hasta el mismo pajarito que avisó entró. Un buen tiempo se quedaron bajo tierra. Después dijo el pajarito que iba a avisar cuando terminase el fuego. Y vino el aviso: "ahora salgan para la tierra”. Dijo el enviado que salgan. Y dijo que cuando subieran no fuesen a mirar para adelante, pues iban a ocurrirles un mal. Y esa gente no escuchó estos consejos. Cuando salieron, no hicieron así y se

\footnotetext{
${ }^{3}$ Luego de la conquista militar del territorio del Gran Chaco, donde históricamente se desplazaban los qom, la economía política argentina se caracterizó por la instalación de un capitalismo periférico orientado a la producción azucarera, maderera y agrícola. Los colectivos indígenas buscaron "acomodarse en el convulsionado territorio, encaminados forzosamente al sedentarismo y al trabajo en las cosechas de caña de azúcar y algodón, principalmente" (CERIANI CERNADAS; LAVAZZA, 2013, p. 147). En este contexto y entre las décadas de 1920 y 1940 se dieron las epidemias de malaria, gripe española, viruela y tuberculosis que diezmaron principalmente a dichos colectivos.
} 
convirtieron en animales. Uno se hizo Koz, el chanco de monte. Otro se levantó y no escuchó lo que le dijo el cacique, miró y se convirtió en Manik, el ñandú. Y así se fueron convirtiendo en Guayaga o zorro gris grande y en diferentes animales. Los que obedecieron lo que dijo el cacique, miraron para abajo y no para adelante y siguieron siendo gente. Los otros ya no eran hombres kom, eran animales del monte, del campo. Se quedaron por ahí. (...) Y como tenían todo esto para comer, la gente estaba contenta y comenzó a crecer y a tener hijos. (...) Hasta aquí, el sufrimiento (TERÁN, 2005, p. 26-27).

Puede haber distintas lecturas, claro está, pero mi pensamiento bricoleur y mis años de estudiante en la 'escuela de la onto-zoología qom' me llevan a pensar en la forma en la cual esta sociedad salió del encierro luego de que la vida, como la conocían hasta ese momento, se había calcinado por completo -cualquier parecido con el fin del verano y el comienzo del otoño del 2020 es mera causalidad-. De bajo tierra salieron seres que, por un lado, guardaban la capacidad de escuchar al mundo animal (es un pajarito el que les avisa que ya puedan salir) y, por otro, ellos también podían alardear de una interioridad humana/no-humana; dicha salida parece señalar que no hay nada excepcional en la capacidad de 'ser gente'; uno sale y, si mira para adelante, pasa a vivir con una familia animal; en cambio, si mira a los costados o hacia abajo, pasa a vivir con una familia humana; pero absolutamente todos en el fondo son gente, ni mejor ni peor, diferente. Entonces me pregunto: ¿no será esta la 'manera', el ‘ejemplo' que podemos empezar a seguir para ir saliendo de debajo de la tierra? ¿No son acaso esas ínfulas de excepcionalismo humano las que nos tienen tan angustiados? ¿Cómo que el Covi-cho -un no-humano, apenas una porción de ADN, ni siquiera una célula-, puede ponernos en jaque a nosotros? ¿No será que la arquitectura de nuestra soberbia nos llevó a desplazar toda y cualquier otra forma de vida hasta convertirnos en una copia tan similar de nosotros mismos que donde se desata un hilo se descose toda la prenda? Creyéndonos únicos e irrepetibles nos multiplicamos biológica y tecnológicamente hasta convertir a la tierra en un monocultivo de nosotros mismos. Sojuzgando toda otra forma de lo que llamamos 'naturaleza' -en definitiva, todo lo que no es humano- construimos un excepcional imperio que, como toda plantación monogenética, necesita de todo tipo de asistencia para sobrevivir

(y aquí podemos enumerar a la ilimitada parafernalia electrónica -desde microchips a lavarropas-, a los antibióticos, los hidrocarburos, la biotecnología, el papel higiénico, y así infinitamente: hagan el ejercicio, es patéticamente divertido).

\section{Simplificaciones finales}

Anna Tsing, una antropóloga estadounidense que estudia paisajes antropocénicos, menciona que los terrícolas humanos construimos nuestras ciudades a través de la simplificación y la destrucción. Edificamos plantations; o sea: extensas áreas donde prospera una única especie a través de la hipertecnificación de su historia vital. La antropóloga 
denuncia que "mutilamos y simplificamos a las plantas cultivadas [a los animales criados iy a nosotros mismos! Agrego yo] hasta que ellas no saben más como participar en mundos de especies múltiples" (TSING, 2019, p. 44). A nuestra imagen y semejanza transformamos, a las formas de vida que necesitamos para existir, en máquinas. Inversamente a lo que ocurre en la historia qom reseñada arriba, las sociedades modernas no caminan hacia la diversificación, sino todo lo contrario. Recordé entonces la triste historia de la 'hambruna de la papa'. Para los que no la conocen, los sucesos comenzaron cuando un hongo infectó a los cultivos de papa mediante los que se sustentaban gran parte de la población de Europa. Así, entre 1845 y 1849, en Irlanda, alrededor de un millón de personas murieron y otro millón más tuvo que partir. Durante la década de 1840 la inanición produjo graves enfermedades y migraciones masivas. Cuando las personas pudieron detenerse a pensar sobre lo ocurrido advirtieron que la falta de variabilidad genética entre las papas y depender de un único cultivo habían sido los factores detonantes de la catástrofe. Y la frase vino a mi mente: ¡Somos papas! Monocultivo de humanos que caminan hacia la simplificación de sus formas de pensar y organizarse en sociedad; ridiculizando las formas indígenas o campesinas, los Estados ensayan 'modelos' simétricamente iguales. El Covi-cho viene a recordarnos casualmente todo eso: no somos para nada excepcionales, nuestras máquinas no nos han redimido de la vulnerabilidad de la que estamos hechos, no probamos más que pocas formas de organizarnos socialmente ¡Somos papas!

Entonces vuelvo al relato qom. Ese 'ejemplo' de fin de mundo nos puede susurrar al oído que la tierra es un ensamble de humanos y no-humanos y que de la caverna corresponde salir multiplicados. Que la ficción que nos llevó a separar a la sociedad de la naturaleza como 'modelo' fracasa completamente en la interpretación del mundo ¡Y fracasa en el sostenimiento de la vida tal como la conocemos! Hoy estamos conviviendo con el Covi-cho y esa pequeña fracción de ADN está volviendo a barajar las cartas de lo que definimos como enemigo. El filósofo de las ciencias Bruno Latour, reflexionando sobre el Antropoceno (LATOUR, 2017), menciona que estamos frente a una inversión total. Si antes los humanos éramos los actores de un telón de fondo llamado naturaleza, ahora la naturaleza es la protagonista y los humanos somos el decorado que debe adaptarse a los vaivenes de esta actriz con sus huracanes, tornados, inundaciones y desertificaciones y calores extremos. ¿Y miren si no estamos siendo la utilería de la dramaturgia de un virus? Para colmo de males somos muchos e iguales y nos hemos aprendido un solo 'modelo' de danza.

En el contexto de estos planteaos algunos científicos han mencionado que la humanidad es una plaga. Rechazo dichos enunciados: los mismos podrían justificar exterminios y ya tenemos suficiente experiencia en esos experimentos sociales que hoy, afortunadamente, son llamados crímenes de lesa humanidad. No somos una plaga, pero si una especie tan frágil y vulnerable como cualquier otra; debemos reconocernos como tales $\mathrm{y}$, como el resto de los organismos, abogar por la multiplicidad como antídoto. Volver a valorar a los 'ejemplos' que aún no han sido arrasados por el 'modelo'; encontrar las maneras en las que los no-humanos se ensamblan en formas ontológicas y sociales que no los excluyan 
$\mathrm{y}$, sobre todo, multiplicar estas formas al ritmo de todos los decires y haceres minoritarios; son mis tips (aparte de lavarse las manos, toser en el hueco del codo y quedarse en la cueva) ante este fin de mundo.

\section{Bibliografía}

CERIANI CERNADAS, Cesar; LAVAZZA, Hugo. (2013). "Fronteras, espacios y peligros en una misión evangélica indígena en el Chaco argentino (1935-1962)”. In: Boletín Americanista, vol. 2, n. 67, pp. 143-162.

FAUSTO, Carlos. (1999). "Of enemies and pets: warfare and shamanism in Amazonia”. In: American Ethnologist, vol. 26, n. 4, pp. 933-956.

LATOUR, Bruno. (2017). Cara a cara con el planeta. Una nueva mirada sobre el cambio climático alejada de las posiciones apocalípticas. Ciudad Autónoma de Buenos Aires: Siglo XXI.

LÉVI-STRAUSS, Claude. (1964). El pensamiento salvaje. México: Fondo de Cultura Económica.

MEDRANO, Celeste. (2013). "Devenir-en-transformación: debates etnozoológicos en torno a la metamorfosis animal entre los qom”. En: TOLA, Florencia; MEDRANO, Celeste; CARDIN, Lorena (Eds.). Gran Chaco. Ontología, poder, afectividad. Buenos Aires, IWGIA/Rumbo Sur, pp. 77-101.

MEDRANO, Celeste. (2014). "Zoo-sociocosmología qom: seres humanos, animales y sus relaciones en el Gran Chaco”. In: Journal de la Societé des Americanistes, vol.100, pp.225257.

MEDRANO, Celeste. (2016a). "Los no-animales y la categoría 'animal'. Definiendo la zoosociocosmología entre los Toba (qom) del Chaco argentino”. In: Mana, vol. 22, n. 2, pp. 369-402.

MEDRANO, Celeste. (2016b). "Hacer a un Perro. Relaciones entre los qom del Gran Chaco Argentino y sus compañeros animales de caza”. In: Anthropos, vol. 111, pp. 113-125

MEDRANO, Celeste. (2019). "Taxonomías relaciones o de que se valen los qom y los animales para clasificarse”. In: Tabula Rasa, vol. 31, pp. 161-183.

TERÁN, Buenaventura. 2005. Lo que cuentan los tobas. Ediciones del Sol, Argentina.

TOLA, Florencia; SUAREZ, Valentín. (2016). El teatro chaqueño de las crueldades. Memorias qom de la violencia y el poder. Buenos Aires: IIGHI / ethnographica / CNRS.

TSING, Anna. (2019). Viver nas ruínas: paisagens multiespécies no Antropoceno. Brasília: IEB/Mil Folhas.

VIVEIROS DE CASTRO, Eduardo. (2019). On Models and Examples Engineers and Bricoleurs in the Anthropocene. In: Current Anthropology, vol. 60, n. 20, pp. 296-308. 
MEDRANO | Ejemplos indígenas el covi-cho y algunos tips anti fines de mundo | 181

sobre la autora

\section{Celeste Medrano}

Investigadora Asistente del CONICET con lugar de trabajo en el Instituto de Ciencias Antropológicas de la Universidad de Buenos Aires. Es doctora em Antropología por la Universidad de Buenos Aires.

Fecha de recepción 30/05/2020

Fecha de aceptación 12/08/2020 